\title{
OPTIMAL ERROR ESTIMATES FOR CORRECTED TRAPEZOIDAL RULES
}

\author{
ERIK TALVILA AND MATTHEW WiERsma
}

Abstract. Corrected trapezoidal rules are proved for $\int_{a}^{b} f(x) d x$ under the assumption that $f^{\prime \prime} \in$ $L^{p}([a, b])$ for some $1 \leqslant p \leqslant \infty$. Such quadrature rules involve the trapezoidal rule modified by the addition of a term $k\left[f^{\prime}(a)-f^{\prime}(b)\right]$. The coefficient $k$ in the quadrature formula is found that minimizes the error estimates. It is shown that when $f^{\prime}$ is merely assumed to be continuous then the optimal rule is the trapezoidal rule itself. In this case error estimates are in terms of the Alexiewicz norm. This includes the case when $f^{\prime \prime}$ is integrable in the Henstock-Kurzweil sense or as a distribution. All error estimates are shown to be sharp for the given assumptions on $f^{\prime \prime}$. It is shown how to make these formulas exact for all cubic polynomials $f$. Composite formulas are computed for uniform partitions.

Mathematics subject classification (2010): Primary 26D15, 41A55, 65D30. Secondary 26A39, 46F10. Keywords and phrases: Numerical integration, quadrature, corrected trapezoidal rule, Lebesgue space, Henstock-Kurzweil integral, Alexiewicz norm, continuous primitive integral.

\section{REFERENCES}

[1] R. G. BARTLE, Elements of integration, New York, Wiley, 1966.

[2] P. R. BEESACK, Bounds for Riemann-Stieltjes integrals, Rocky Mountain J. Math. 5 (1975), 75-78.

[3] V. G. ČELIDZE AND A. G. DŽVARŠĚ̌̌̌ VILI, The theory of the Denjoy integral and some applications (trans. P. S. Bullen), Singapore, World Scientific, 1989.

[4] P. Cerone And S. S. Dragomir, Trapezoidal-type rules from an inequalities point of view, in: G. Anastassiou (Ed.), Handbook of analytic-computational methods in applied mathematics, New York, CRC Press, 2000, pp. 65-134.

[5] E. W. ChENEY, Introduction to approximation theory, New York, Chelsea, 1982.

[6] R. B. Darst And H. Pollard, An inequality for the Riemann-Stieltjes integral, Proc. Amer. Math. Soc. 25 (1970), 912-913.

[7] P. J. DAVIS, Interpolation and approximation, New York, Blaisdell, 1963.

[8] P. J. Davis AND P. RaBinowitz, Methods of numerical integration, New York, Dover, 2007.

[9] Lj. Dedić, M. Matić And J. PeČArić, On Euler trapezoid formulae, Appl. Math. Comput. 123 (2001), 37-62.

[10] X. Ding, G. YE, W.-C. YANG, Estimates of the integral remainders in several numerical integral formulas using the Henstock-Kurzweil integral, J. Math. Inequal. 3 (2009), 243-256.

[11] J. Gillis AND G. LeWis, Monic polynomials with minimal norm, J. Approx. Theory 34 (1982), 187-193.

[12] P.-Y. LEE, Lanzhou lectures on Henstock integration, Singapore, World Scientific, 1989.

[13] E. H. Lieb AND M. Loss, Analysis, Providence, American Mathematical Society, 2001.

[14] Z. LiU, Error estimates for some composite corrected quadrature rules, Appl. Math. Lett. 22 (2009), $771-775$.

[15] G. G. Lorentz, Approximation of functions, Providence, American Mathematical Society, 2005.

[16] National Institute of Standards and Technology, Digital Library of Mathematical Functions. Release date 2010-05-07. From http://dlmf .nist.gov/.

[17] J. PEČARIĆ AND N. UJEVIĆ, A representation of the Peano kernel for some quadrature rules and applications, Proc. R. Soc. Lond. Ser. A Math. Phys. Eng. Sci. 462 (2006), 2817-2832. 
[18] M. Riesz And A. E. Livingston, A short proof of a classical theorem in the theory of Fourier integrals, Amer. Math. Monthly 62 (1955), 434-437.

[19] E. Talvila, Henstock-Kurzweil Fourier transforms, Illinois J. Math. 46 (2002), 1207-1226.

[20] E. Talvila, The distributional Denjoy integral, Real Anal. Exchange 33 (2008), 51-82.

[21] E. Talvila, The regulated primitive integral, Illinois J. Math. 53 (2009), 1187-1219.

[22] E. Talvila And M. Wiersma, Simple derivation of basic quadrature formulas, Atl. Electron. J. Math. (to appear). 